\title{
The Classification of Synoptic-Scale Eddies at 850 hPa over the North Pacific in Wintertime
}

\author{
Linlin Xia, ${ }^{1}$ Yanke Tan, ${ }^{1}$ Chongyin Li, ${ }^{1,2}$ and Cheng Cheng ${ }^{3}$ \\ ${ }^{1}$ Meteorological and Oceanography College, PLA University of Science and Technology, Nanjing 211101, China \\ ${ }^{2}$ LASG, Institute of Atmospheric Physics, Chinese Academy of Sciences, Beijing 100029, China \\ ${ }^{3}$ PLA, Unit 95178, Nanning 530226, China \\ Correspondence should be addressed to Yanke Tan; polaristan@163.com
}

Received 25 April 2016; Revised 19 July 2016; Accepted 2 August 2016

Academic Editor: Anthony R. Lupo

Copyright (c) 2016 Linlin Xia et al. This is an open access article distributed under the Creative Commons Attribution License, which permits unrestricted use, distribution, and reproduction in any medium, provided the original work is properly cited.

Empirical orthogonal function (EOF) is applied to the study of the synoptic-scale eddies at $850 \mathrm{hPa}$ over the North Pacific in winter from 1948 to 2010. The western developing pattern synoptic-scale eddies (WSE) and the eastern developing pattern synoptic-scale eddies (ESE) are extracted from the first four leading modes of EOF analysis of high-pass filtered geopotential height. The results show the following: (1) The WSE and the ESE both take the form of a wave train propagating eastward. The WSE reach their largest amplitude around the dateline in the North Pacific, while the largest amplitude of ESE occurs in the northeast Pacific. (2) The WSE and ESE are the most important modes of the synoptic-scale eddies at $850 \mathrm{hPa}$ over the North Pacific, which correspond to the two max value centers of the storm track. (3) In addition to geopotential height, the WSE and the ESE also leave their wavelike footprints in the temperature, meridional wind, and vertical velocity fields, which assume typical baroclinic wave features. (4) The WSE and the ESE have an intrinsic time scale of four days and experience a "midwinter suppression" corresponding to the midwinter suppression of storm tracks.

\section{Introduction}

Synoptic-scale eddies/storm tracks are very active in the North Pacific in winter. These transient eddies are mainly associated with baroclinic waves which migrate eastward in the westerly flow. The activity of these transient eddies can be measured by the variance in geopotential height, eddy kinetic energy, or meridional heat transport based on their highpass temporal filtered time series. The maxima of measured eddy activities are observed in a zonal region above the North Pacific in winter (Figure 1). The zonal regions which are also consistent with cyclone activities on the ground are called "storm tracks," so the storm tracks show the statistical character of the synoptic-scale eddies [1-4].

The spatial structure and temporal evolution of storm track have been investigated by some previous studies. Hoskins et al. [5] showed a schematic three-dimensional distribution of winter storm tracks in the Northern Hemisphere. Zhu and Sun [6] suggested that the structures in the western and eastern segments of the storm track over the North Pacific are different. They also pointed out that the difference of baroclinicity between the western and eastern segments is the main cause [7]. Fu et al. [8] confirmed that the storm tracks in the west and east of the North Pacific are obviously different by plotting the three-dimensional schematic diagrams of storm track in winter.

Because of the phenomenon that a big difference exists between the west and east segments of the storm tracks over North Pacific, the classification of the synoptic-scale eddies/ storm tracks has received much attention and it remains a topic of great importance to explain the phenomenon. The first two modes of the Pacific storm track variability consist of a monopole that represents variability in the overall intensity of the storm track and a dipole that represents shifting of the climatological-mean storm track in the meridional direction [9-11]. Ren et al. [12] suggested that the two main variation models of storm track in the North Pacific in winter are related to PNA and WP in mid and high troposphere. In addition, the storm track over the North Pacific always became weakest during midwinter, which is known as "midwinter suppression" $[3,13]$. 


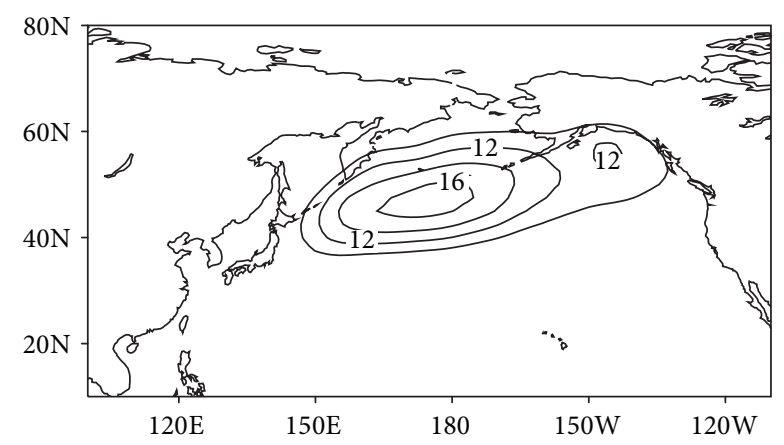

FIGURE 1: Spatial distributions of mean variance of synoptic-scale geopotential height (unit: dagpm ${ }^{2}$ ) at $850 \mathrm{hPa}$ in winter from 1948 to 2010 .

Recently, Jiang and Tan [14] showed two main modes of baroclinic waves based on meridional wind at $250 \mathrm{hPa}$ by using termed moving empirical orthogonal function analysis (MEOF). The seasonal and interannual variation of the storm tracks are also argued in their paper. It is still unclear about how the main modes of synoptic-scale eddies exist in the low troposphere. In this study, we address this issue by analyzing $850 \mathrm{hPa}$ typical synoptic eddies in the wintertime over the North Pacific. The synoptic eddies from 1948 to 2010 are investigated by using empirical orthogonal function (EOF). Two modes of the synoptic-scale eddies are classified based on the first four EOF modes. Then the details of the classification are presented.

This paper is arranged as follows: The method and data used are introduced in Section 2. Details of the results are described in Section 3. A discussion and concluding remarks are presented in Section 4.

\section{Data and Methods}

The datasets used in this work include National Centers for Environmental Prediction-National Center for Atmospheric Research (NCEP-NCAR) reanalysis 1948-2011 daily circulation data [15], including geopotential height, air temperature, zonal wind, meridional wind, and vertical velocity.

A Lanczos filter with 31 weights [16] was applied to the data time series on each grid, for separating the synopticscale (2.5-6 days) component. Winter in this paper comprises three months: December, January, and February (DJF). The data used in this study ranges from December 1948 to February 2011. Particularly, in every February, only the days from 1st of February to 28th of February are chosen. The EOF analysis, like Megan and Sumant [17], is also used in this paper.

\section{The Classification of the Synoptic-Scale Eddies}

Daily weather variations in the mid-latitude are mainly related with the synoptic-scale eddies, so the synoptic-scale eddies always change fast when they migrate eastward. The first four leading EOF modes are derived by performing an EOF analysis of the synoptic-scale geopotential height at
$850 \mathrm{hPa}$ during the winter of 1948-2010. The EOF spatial patterns are presented in Figure 2. The four leading modes (hereafter EOF1, EOF2, EOF3, and EOF4) explain 12.3\%, $11.9 \%, 7.4 \%$, and $6.6 \%$ of the total variance, respectively. For propagating waves, the EOFs always show the migrating character by appearing in pairs. The EOF1 and EOF2 are statistically distinct from each other [18], and they are in different phases ( $\pi / 2$ phase difference) for the same propagating wave, so as EOF3 and EOF4. The wave presented by EOF1 and EOF2 with the maximum center located in the area west to the date line can be called western developing pattern synoptic-scale eddies (hereafter WSE). The WSE propagate from southwest Japan to northeast Pacific. The figures of time series corresponding to EOF1 and EOF2 ( $\mathrm{PCl}$ and $\mathrm{PC} 2$, in which PC is short for principal component) are omitted. The table (Table 1) of lead-and-lag correlation coefficient of PC1 and PC2 indicates that the positive correlation coefficient climbs to the top when PC1 lags PC2 for 1 day, while the negative correlation coefficient falls to the bottom when PC1 leads PC2 for 1 day. Because of the orthogonality between EOF1 and EOF2, PC1 lags PC2 for 1/4 period, so the period of the fluctuation is about 4 days. For the propagating wave, we can conclude that the WSE develop from Japan to the nearby of date line; then they weaken after moving across the date line.

Just like EOF1 and EOF2, EOF3 and EOF4 have similar results; the wave presented by EOF3 and EOF4 can be called eastern developing pattern synoptic-scale eddies (hereafter ESE), because its maximum center locates in the area east to the date line where it is near the coast of North America. The ESE propagate from the west of the North Pacific to the east and then develop in the east of the North Pacific. The wave features in the WSE are consistent with the previous study [14].

Nevertheless, one may still query about the two modes of synoptic-scale eddies classified by EOF analysis. To confirm the synoptic character of the WSE and the ESE, the composition of some typical samples chosen based on PCs is obtained. The typical samples of the WSE are chosen to represent the WSE in the condition that standardized PC1 $>2$ or PC2 $>2$, and the typical samples of the ESE are chosen to represent the ESE in the condition that standardized PC $3>2$ or PC $4>2$.

Given the fact that the period of the synoptic-scale eddies is around 4 days, the composite of height perturbations, horizontal wind perturbations, temperature perturbations, and vertical velocity perturbations based on PC1 (Figures 4(a)4(e)) and PC2 (Figures 4(f)-4(j)) are calculated for five days in a row. All the perturbations propagated eastward over the North Pacific and reached their largest amplitude around the dateline and then weakened. In addition, the distribution of the perturbations with lags -2 days based on PC1 (Figure $3(\mathrm{a})$ ) is the same as the distribution of the perturbations with lag -1 day based on PC2 (Figure 3(g)), which indicate that the EOF1 and EOF2 both showed the character of the WSE, and EOF2 lags behind EOF1 for 1 day. (According to the orthogonality, we can also get that the phase difference between EOF1 and EOF2 is $\pi / 2$.) The composition of the two kinds of samples showed the same distributions with lags -2 days and lags 2 days, so we can conclude that the period of the 


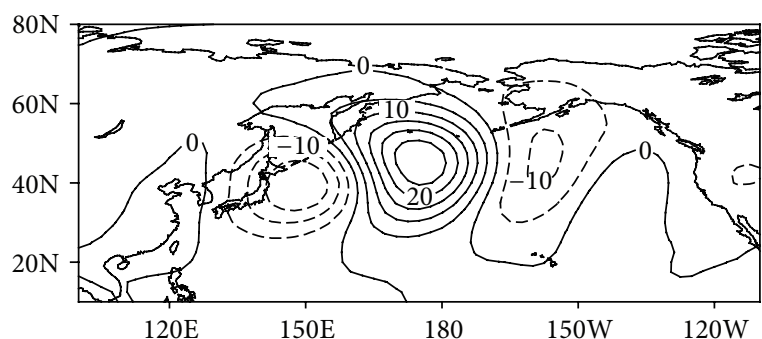

(a)

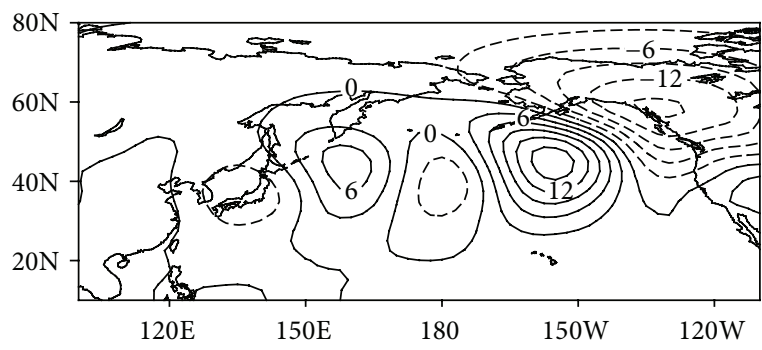

(c)

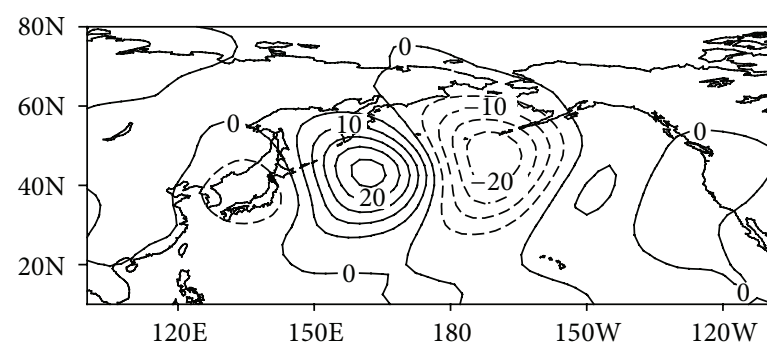

(b)

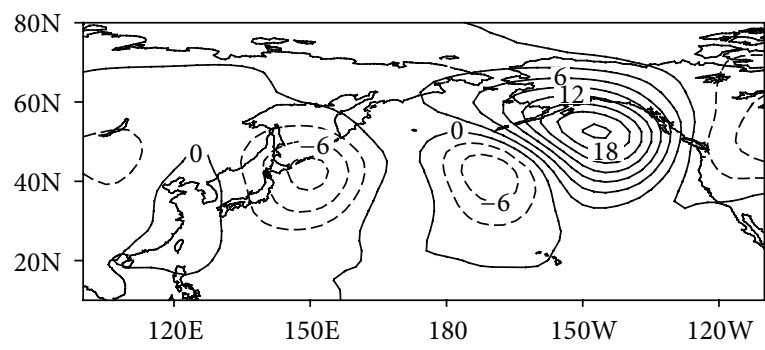

(d)

Figure 2: Spatial patterns of the first four leading EOF modes of the synoptic-scale eddy at $850 \mathrm{hPa}$ in winter from 1948 to 2010 ((a) EOF1, (b) EOF2, (c) EOF3, and (d) EOF4, unit: gpm).

TABLE 1: Lead and lag correlation coefficient among PCs.

\begin{tabular}{lccccccccccc}
\hline Lag (days) & -5 & -4 & -3 & -2 & -1 & 0 & 1 & 2 & 3 & 4 \\
\hline PC1/PC2 & -0.15 & 0.15 & 0.52 & -0.08 & -0.83 & -0.03 & 0.82 & 0.08 & -0.49 & -0.15 & 0.11 \\
PC3/PC4 & -0.08 & -0.16 & -0.36 & -0.10 & 0.64 & -0.02 & -0.66 & -0.09 & 0.40 & 0.16 & -0.1 \\
\hline
\end{tabular}

WSE is about four days, which is consistent with the result of Table 1.

As shown in Figure 3, the temperature perturbations always lag behind the height perturbations in the process of propagating eastward, which is a main character of baroclinic waves. In addition, the changes of temperature perturbations were in accordance with the changes of height perturbations in intensity. Furthermore, the temperature perturbations and vertical velocity perturbations travel in the opposite phases. In other words, the cold air sinks and the warm air ascends, which is also in favor of the release of the available potential energy.

Just like the analysis of Figure 3, as shown in Figure 4, we can conclude that EOF3 and EOF4 both present the character of the ESE, and EOF3 lags behind EOF4 for 1 day. We can also find that the ESE have the characters of the baroclinic waves and the period of the ESE is about 4 days. In addition to height and temperature, the WSE and the ESE also leave their wavelike footprints in the meridional wind and vertical velocity perturbations, as shown in Figure 4. Furthermore, through comparing the composite results, the strength of the WSE is obviously stronger than the ESE.

The storm variability presented by the WSE is active over the North Pacific $[9,11,14]$, while the ESE related variability was seldom discussed previously. In fact, the WSE and the ESE can be frequently detected in wintertime in North Pacific. Figure 5 shows an example of the WSE that appeared from December 10th to December 13th in 1983. On
December 10th, a distinct wave train pattern formed around the central North Pacific region and propagated eastward. Then, it propagated until December 13th and weakened. During the period, the largest amplitude always located in the west of the dateline. Figure 6 shows an example of the ESE that appeared from January 15th to January 18th in 1991. On January 15 th, a distinct wave train pattern formed around the northeast Pacific region and propagated eastward, while the synoptic-scale eddies in the northwest Pacific are weaker. Then they propagated until January 18th; the synoptic-scale eddies in the northwest Pacific became stronger. During the process of propagating, the region of the largest amplitude located in the areas around the northeast Pacific. In addition, as shown in Figures 5 and 6, the two modes of the synopticscale eddies have an intrinsic time scale of four days.

In the real atmosphere, the synoptic-scale eddies with high complexity consist mainly of one or more modes of EOFs. The WSE and ESE are the most important developing modes of the synoptic-scale eddies at $850 \mathrm{hPa}$ over the North Pacific. In order to investigate the synoptic and climatic character by separating the WSE and ESE, respectively, the indexes of the WSE and ESE are defined as PCW = $\sqrt{\mathrm{PC}^{2}+\mathrm{PC}^{2}}$ and $\mathrm{PCe}=\sqrt{\mathrm{PC} 3^{2}+\mathrm{PC}^{2}}$. In order to show the relationship among $\mathrm{PCW}$ and $\mathrm{PC} 1$ and $\mathrm{PC} 2$, a random time series from 1 December 1948 to 28 February 1949 is chosen (Figure 7). In view of the orthogonality between EOF1 and EOF2, PC1 always reaches its peak one day later than PC2. As shown in Figure 7, the PCw can assume the variation of the 


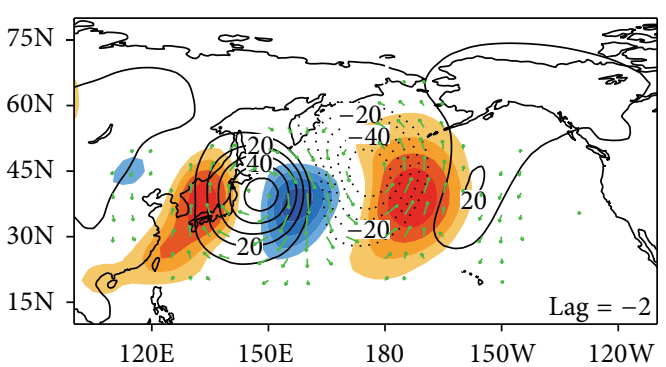

(a)

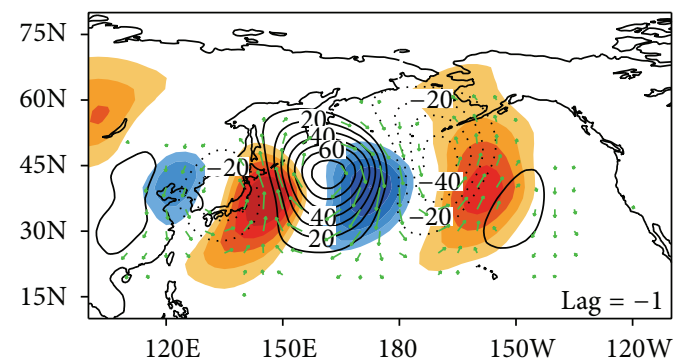

(b)

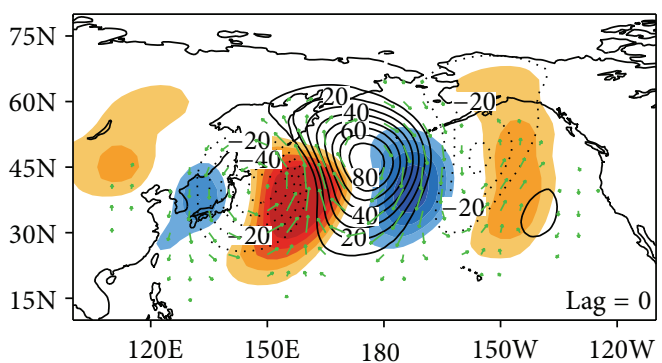

(c)

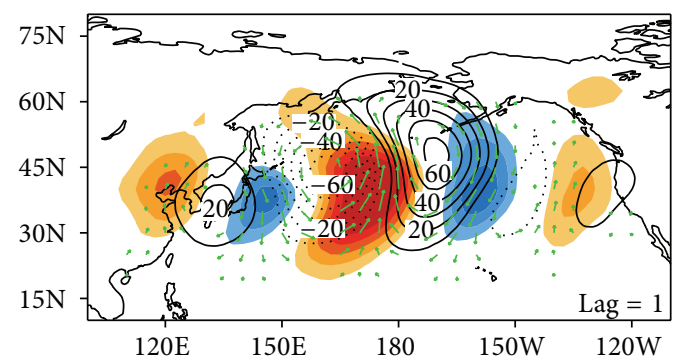

(d)

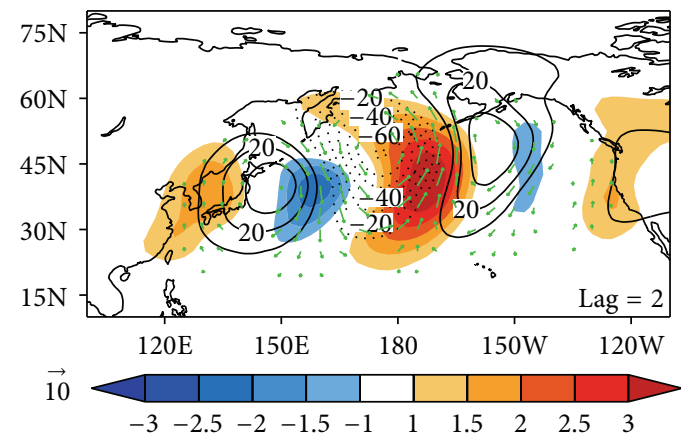

(e)

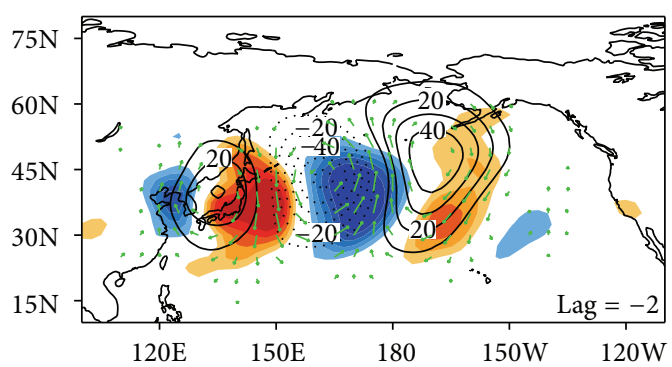

(f)

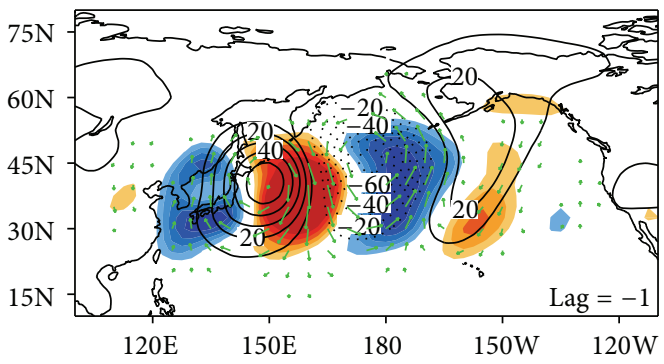

(g)

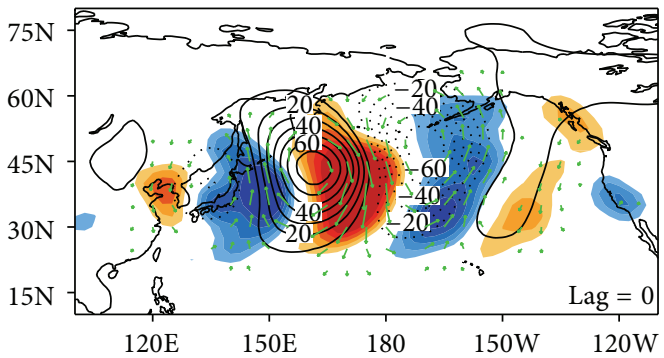

(h)

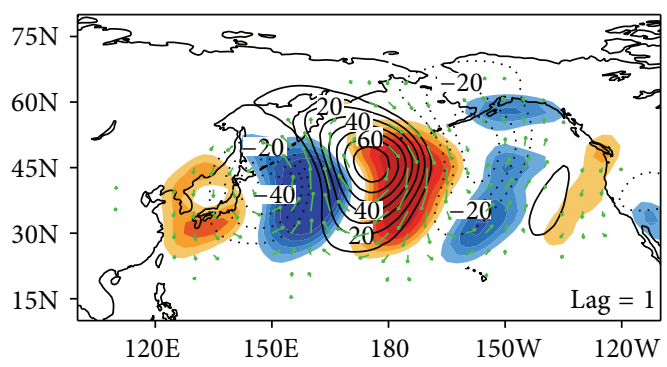

(i)

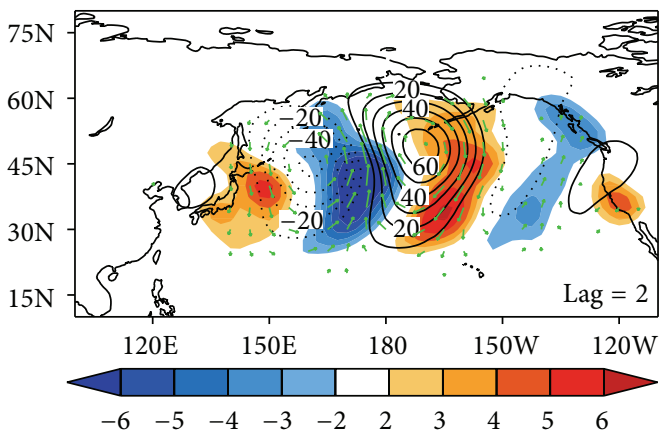

(j)

FIGURE 3: The height perturbations (contour, unit: gpm), horizontal wind perturbations (vector, unit: $\mathrm{m} / \mathrm{s}$ ), temperature perturbations (shaded in (a)-(e), unit: K), and vertical velocity perturbations (shaded in (f)-(j), unit: $\left.10^{-2} \mathrm{~Pa} / \mathrm{s}\right)$ of the typical samples $(\mathrm{PC1}>2$ : $(\mathrm{a})-(\mathrm{e})$; $\mathrm{PC} 2>2$ : $(\mathrm{f})-(\mathrm{j}))$, in which lag $=-2$ corresponds to two days before the typical samples and so on. 


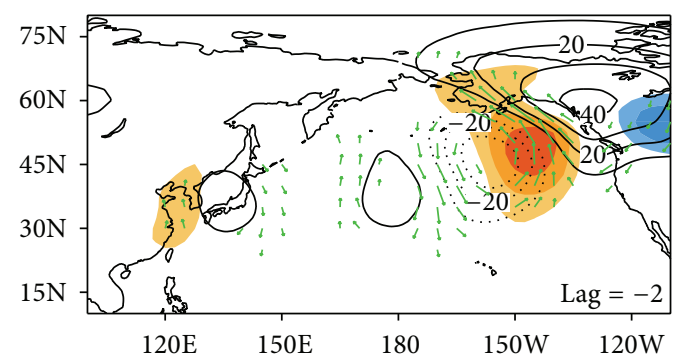

(a)

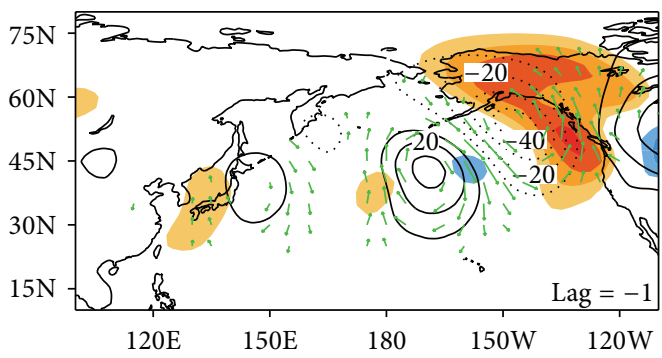

(b)

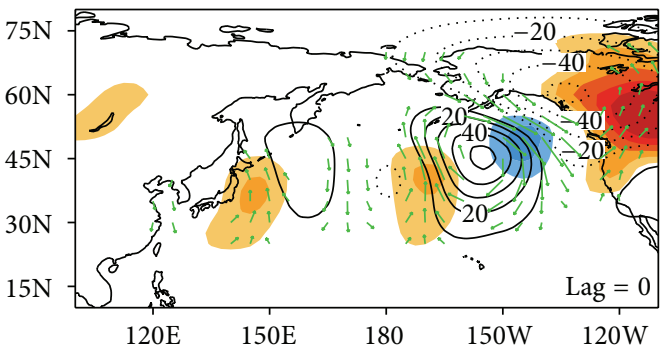

(c)

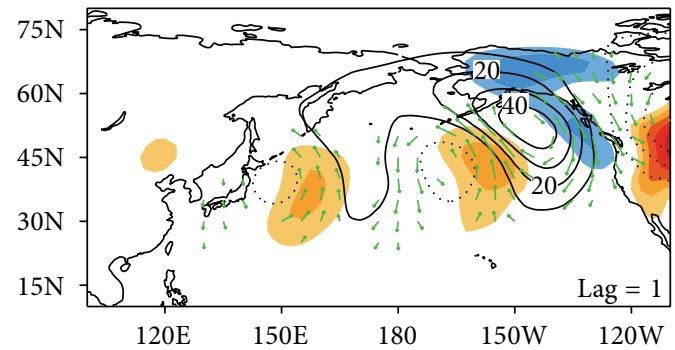

(d)

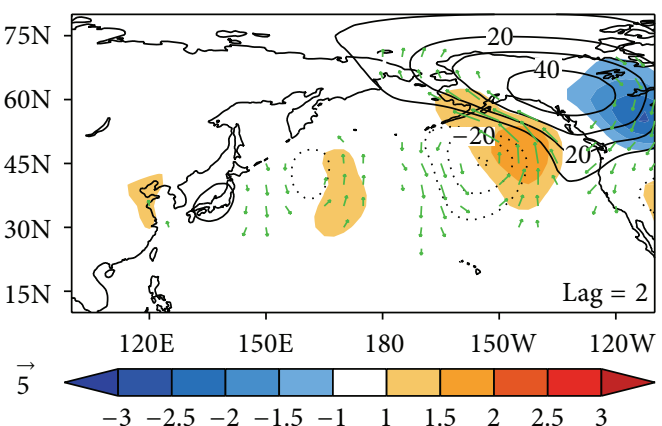

(e)

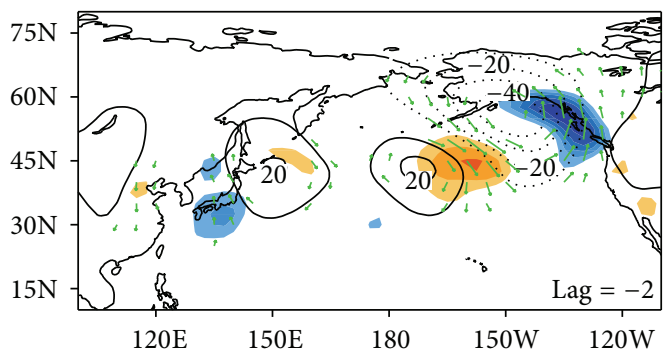

(f)

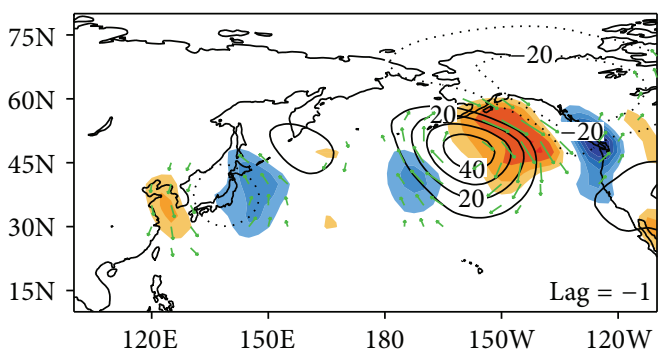

(g)

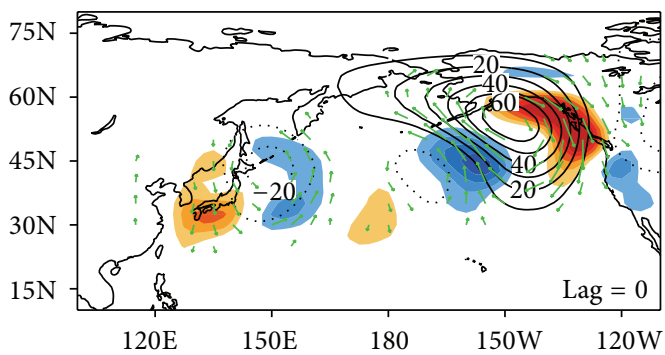

(h)

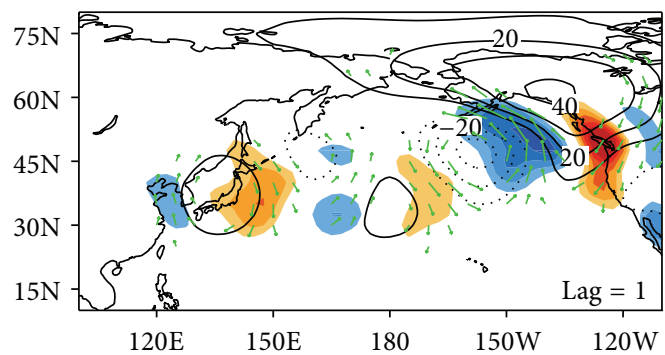

(i)

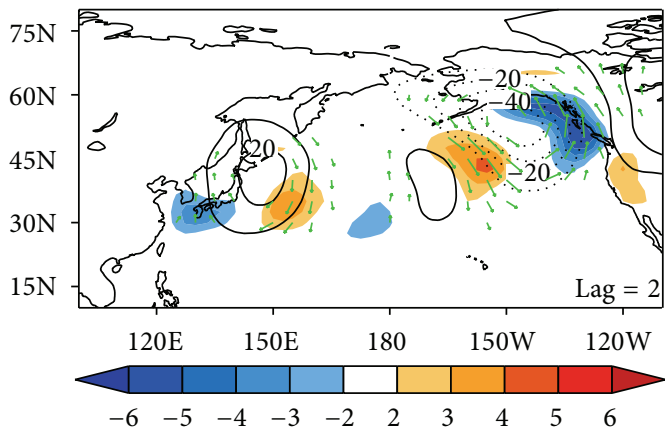

(j)

Figure 4: As in Figure 3, but for the PC3 > 2 (a, b, c, d, and e) and PC4 $>2$ (f, g, h, i, and j). 


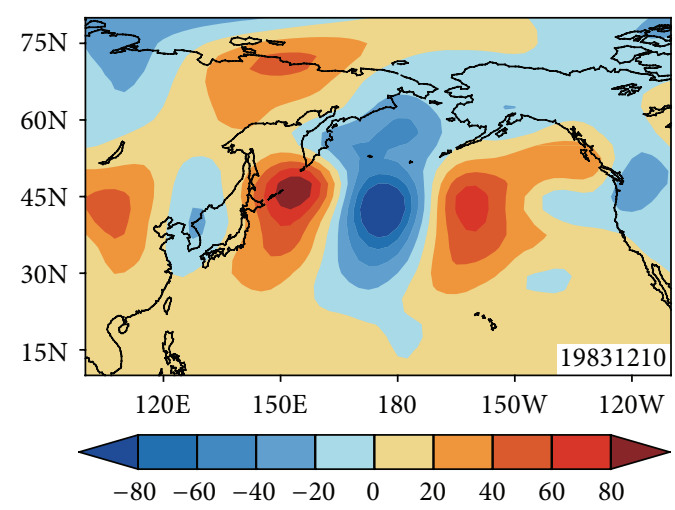

(a)

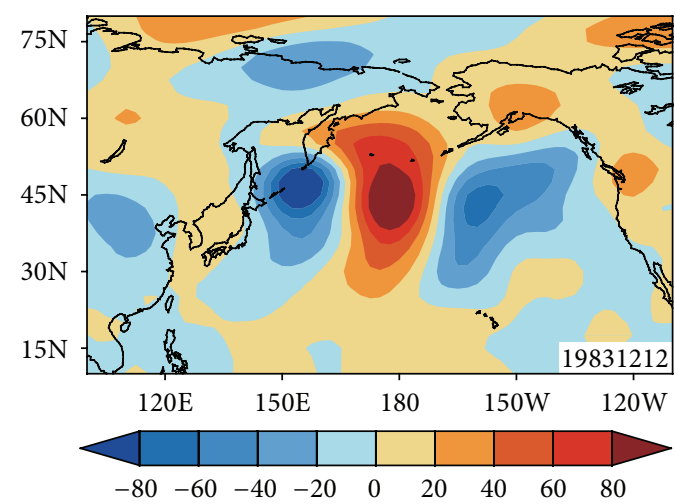

(c)

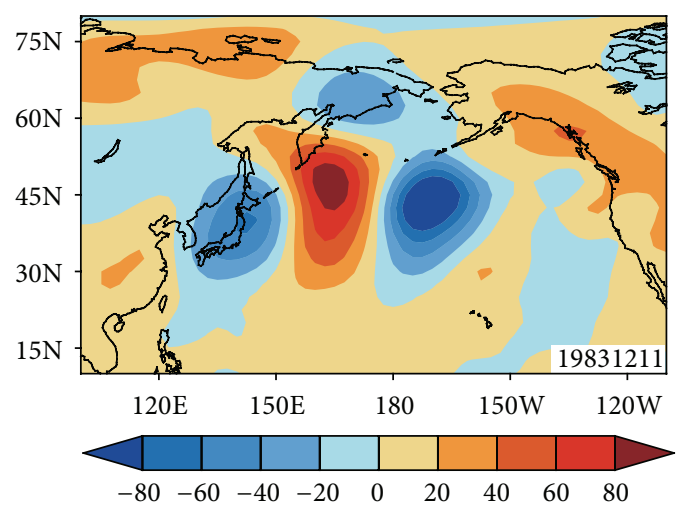

(b)

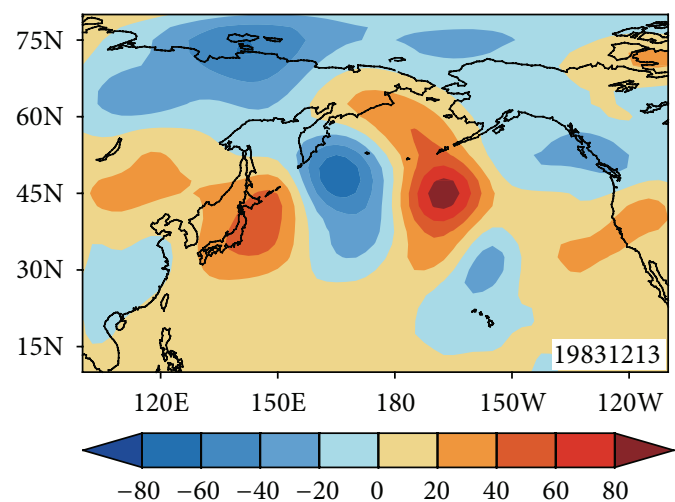

(d)

FIGURE 5: The synoptic-scale geopotential height perturbations at $850 \mathrm{hPa}$ from 10 to 13 December 1983 (unit: gpm).

PC1 and PC2, and the PCw reaches its peak corresponding to the strong WSE. This example indicated that the PCW can be used to present the intensity of the WSE. For the same reason, using the PCe to present the intensity of the ESE is also reasonable.

To confirm the relationship between the storm tracks and the synoptic-scale eddies, the monthly indices of the WSE and ESE are calculated by averaging the $\mathrm{PCw}$ and PCe of every month in winter from 1948 to 2010. The months, in which the WSE are the primary mode (hereafter with strong WSE), are chosen when the standardized monthly index of the WSE is greater than 1 and the standardized monthly index of the ESE is less than 0 , so as the months with strong ESE. Then 14 months with strong WSE and 13 months with strong ESE are chosen to compare the storm tracks of each other (Figure 8).

As shown in Figure 8, the WSE related storm track (Figure $8(\mathrm{a})$ ) distributes in a belt from the west to the east in the North Pacific. The maximum center locates in the west of the North Pacific which is above 24 dagpm $^{2}$. However, the maximum center of the ESE related storm track locates in the northeast Pacific and the maximum is obviously smaller than the former (Figure 8(b)), which is consistent with the two maximum centers showed by Figure 1 . In view of the variance contribution of the EOFs, we can conclude that the WSE related storm track represents the primary storm tracks in the North Pacific, and the ESE related storm track represents the secondary storm track, corresponding to the distribution of the mean state of storm track.

In other words, if the WSE are predominant in a month, then the storm track shows the character that the maximum center locates in the west of the North Pacific; if the ESE are predominant in a month, the maximum center of the storm track would locate in the east of the North Pacific. However, if there is no predominant pattern in a month, the spatial distribution of the storm track would be complex.

The WSE and the ESE are the two primary modes of synoptic-scale eddies over the North Pacific, and the PCw and the PCe can be used to present the intensity of them; then the seasonal variability can also be derived from the two time series of the WSE and ESE. Figure 9 shows the seasonal variability of the WSE and the ESE, respectively, which are obtained simply by averaging the time series (PCw and PCe) for the same calendar day for the period of 19482010. Obviously, the PCw and PCe fall to the bottom around January, which is known as the "midwinter suppression" [3].

\section{Summary and Discussion}

By using the EOF analysis, the WSE and ESE at $850 \mathrm{hPa}$ over North Pacific are obtained, which are the two most important modes of synoptic-scale eddies. The characters of the two 


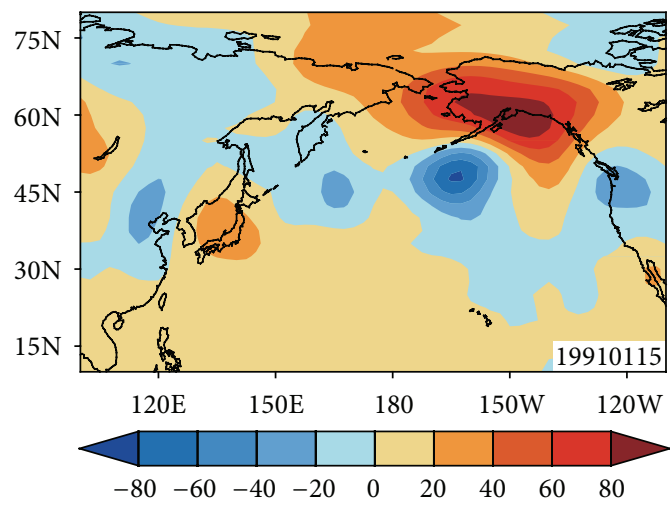

(a)

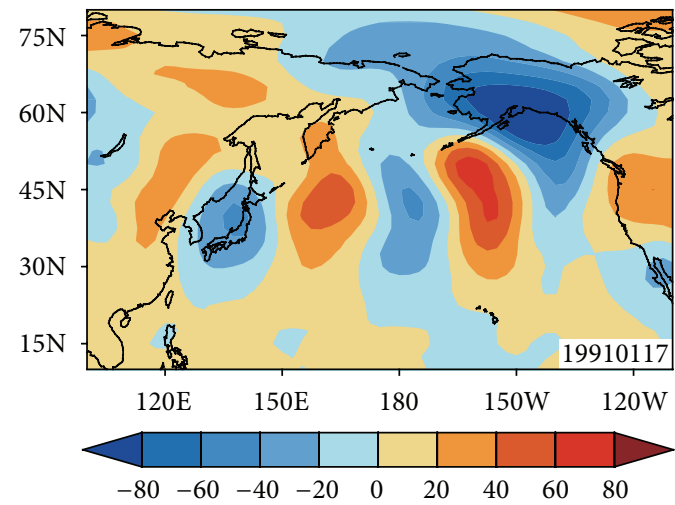

(c)

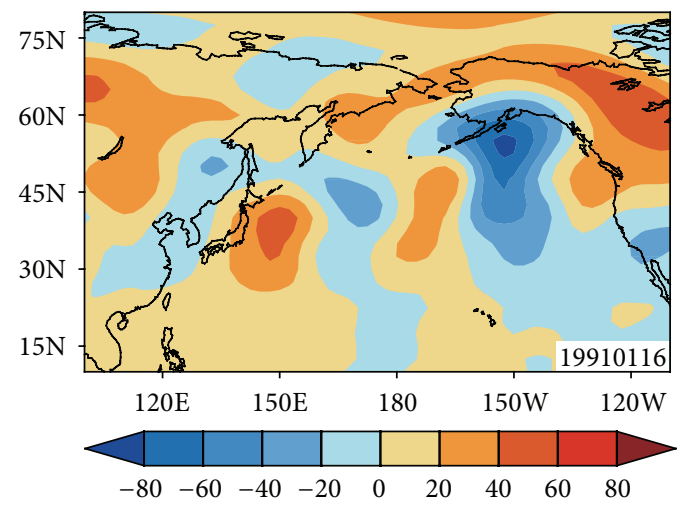

(b)

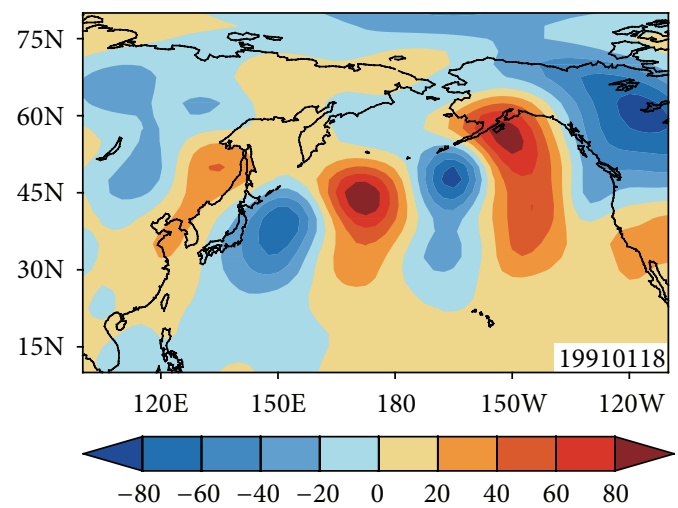

(d)

FIgURE 6: The synoptic-scale geopotential height perturbations at $850 \mathrm{hPa}$ from 15 to 18 January 1991 (unit: gpm).

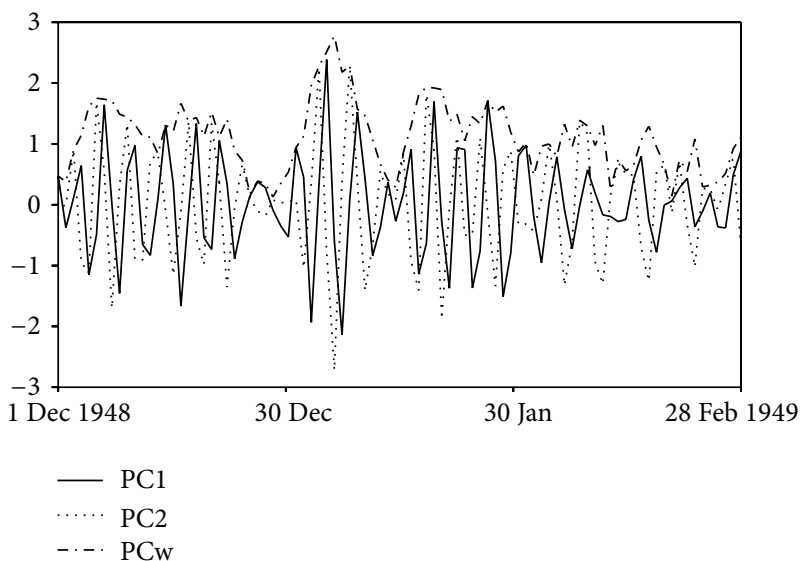

Figure 7: The PCw, PC1, and PC2 from 1 December 1948 to 28 February 1949 (solid line: PC1, pecked line: PC2, and dash-dot: PCw, unit: 1).

modes of transient eddies are discussed in this study. The following conclusions have been reached.

The EOF1 and EOF2 assume a wave train-like pattern (the WSE) propagating eastward, which reaches its largest amplitude around the dateline in the North Pacific. The EOF3 and EOF4 also assume a wave train-like pattern (the ESE) propagating eastward, which developed in the east of the North Pacific. The results indicate that the WSE and the ESE are the two most important modes of synoptic-scale eddies at $850 \mathrm{hPa}$ over the North Pacific, and the WSE is stronger than the ESE in intensity. The composites of the variables, such as geopotential height, temperature, meridional wind, and vertical velocity show that the WSE and the ESE represent typical baroclinic waves. These two modes of the synopticscale eddies have an intrinsic time scale of four days.

The activities of the WSE and the ESE well explained the two maximum centers in the mean state of the storm track at $850 \mathrm{hPa}$ over the North Pacific. Furthermore, the distributions of storm track mainly depend on the activities of the WSE and the ESE. In addition, the WSE and the ESE experience a "midwinter suppression" corresponding to the midwinter suppression of storm tracks.

In this paper, we discussed the characters of the two main modes of transient eddies and their relationship with storm tracks; however, the mechanisms of the WSE and the ESE are still unclear. For future work, it will be necessary to determine the mechanisms of the WSE and the ESE. These outstanding issues may require further discussion in future papers.

\section{Competing Interests}

The authors declare no conflict of interests. 


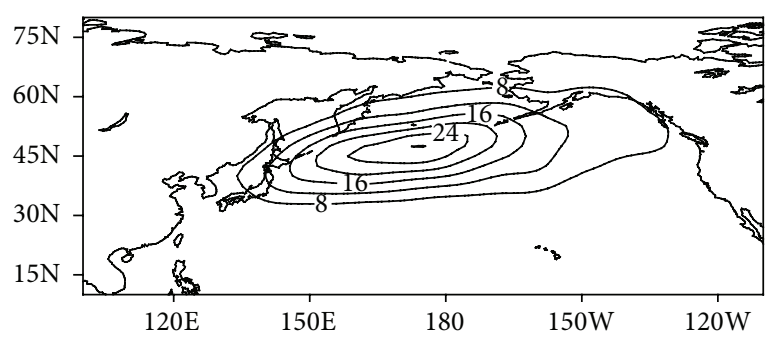

(a)

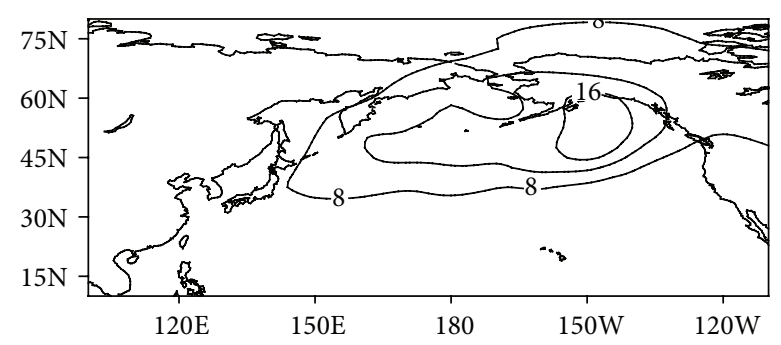

(b)

FIGURE 8: The WSE related storm track (a) and the ESE related storm track (b), which are obtained based on the monthly index of PCw and PCe (unit: dagpm ${ }^{2}$ ).

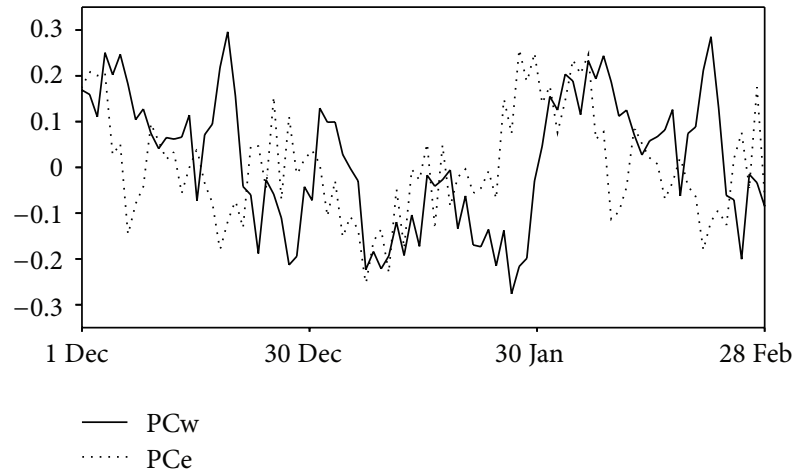

FIGURE 9: The variability of the WSE and ESE (solid line: PCw, pecked line: PCe) for the winters of 1948-2010, which are obtained through the same calendar day mean of PCw and PCe (standardized, unit: 1).

\section{Acknowledgments}

This work was supported by the Chinese Key Developing Program for Basic Sciences (2013CB956203) and National Natural Science Foundation of China (41490642, 41475070).

\section{References}

[1] M. L. Blackmon, J. M. Wallace, N. Lau, and S. L. Mullen, "An observational study of the northern hemisphere wintertime circulation," Journal of the Atmospheric Sciences, vol. 34, no. 7, pp. 1040-1053, 1977.

[2] B. J. Hoskins and P. J. Valdes, "On the existence of storm-tracks," Journal of the Atmospheric Sciences, vol. 47, no. 15, pp. 1854-1864, 1990.

[3] H. Nakamura, "Midwinter suppression of baroclinic wave activity in the Pacific," Journal of the Atmospheric Sciences, vol. 49, no. 17, pp. 1629-1641, 1992.

[4] D. Hotta and H. Nakamura, "On the significance of the sensible heat supply from the ocean in the maintenance of the mean baroclinicity along storm tracks," Journal of Climate, vol. 24, no. 13, pp. 3377-3401, 2011.

[5] B. J. Hoskins, I. N. James, and G. H. White, "The shape, propagation and mean-flow interaction of large-scale weather systems," Journal of the Atmospheric Sciences, vol. 40, no. 7, pp. 1595-1612, 1983.
[6] W. J. Zhu and Z. B. Sun, "Storm track study," Jounal of Nanjing institute of Meteorology, vol. 22, no. 1, pp. 121-127, 1999.

[7] W. J. Zhu, K. Yuan, and Y. N. Chen, "Spatial and temporal variations in the eastern North Pacific storm track," Chinese Journal of Atmospheric Sciences, vol. 37, no. 1, pp. 65-80, 2013.

[8] G. Fu, W. Bi, and J. T. Guo, "Three-dimensional structure and low-level features of the North Pacific storm track from 19992005," Acta Mechanica Sinica, vol. 23, no. 3, pp. 276-289, 2009.

[9] N. C. Lau, "Variability of the observed midlatitude storm tracks in relation to low-frequency changes in the circulation pattern," Journal of the Atmospheric Sciences, vol. 45, no. 19, pp. 27182743, 1988.

[10] E. K. M. Chang and Y. Fu, "Interdecadal variations in Northern Hemisphere winter storm track intensity," Journal of Climate, vol. 15, no. 6, pp. 642-658, 2002.

[11] J. J. Wettstein and J. M. Wallace, "Observed patterns of monthto-month storm-track variability and their relationship to the background flow," Journal of the Atmospheric Sciences, vol. 67, no. 5, pp. 1420-1437, 2010.

[12] X.-J. Ren, X.-Q. Yang, B. Han, and G.-Y. Xu, "Storm track variations in the North Pacific in winter season and the coupled pattern with the midlatitude atmosphere-ocean system," Chinese Journal of Geophysics, vol. 50, no. 1, pp. 92-100, 2007.

[13] E. K. M. Chang, "GCM and observational diagnoses of the seasonal and interannual variations of the Pacific storm track during the cool season," Journal of the Atmospheric Sciences, vol. 58, no. 13, pp. 1784-1800, 2001.

[14] Y. X. Jiang and B. K. Tan, "Two modes and their seasonal and interannual variation of the baroclinic waves/storm tracks over the wintertime North Pacific," Advances in Atmospheric Sciences, vol. 32, no. 9, pp. 1244-1254, 2015.

[15] E. Kalnay, M. Kanamitsu, R. Kistler et al., "The NCEP/NCAR 40-year reanalysis project," Bulletin of the American Meteorological Society, vol. 77, no. 3, pp. 437-471, 1996.

[16] J. Wei and W. J. Zhu, "Comparison of two filtering ways for synoptic scale transient-waves," Journal of Nanjing Institute of Meteorology, vol. 29, no. 4, pp. 549-554, 2006.

[17] E. L. Megan and N. Sumant, "The North Pacific oscillation West Pacific teleconnection pattern: mature-phase structure and winter impacts," Journal of Climate, vol. 5, pp. 1979-1997, 2008.

[18] G. R. North, T. L. Bell, R. F. Cahalan, and F. J. Moeng, "Sampling errors in the estimation of empirical orthogonal functions," Monthly Weather Review, vol. 110, no. 7, pp. 699-706, 1982. 

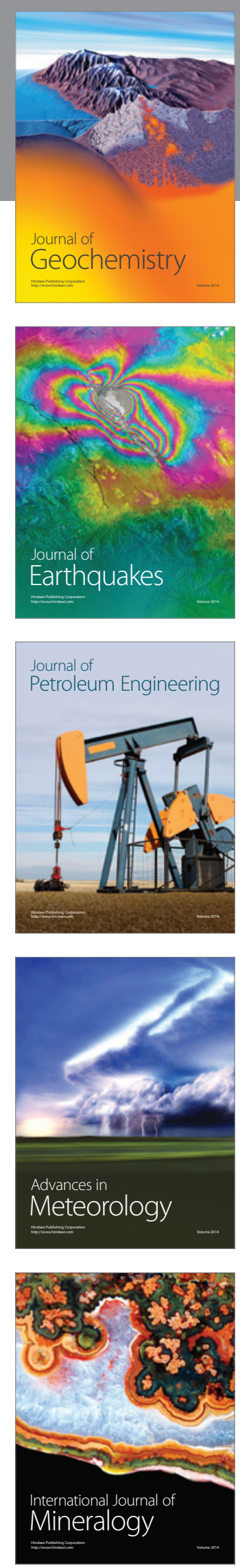
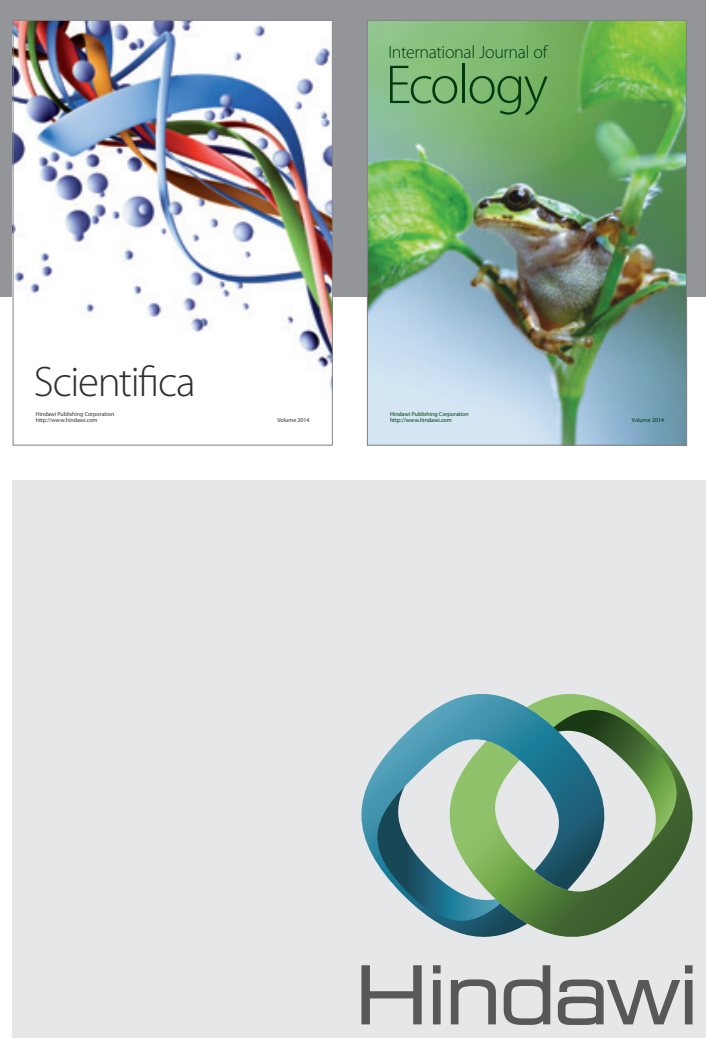

Submit your manuscripts at

http://www.hindawi.com
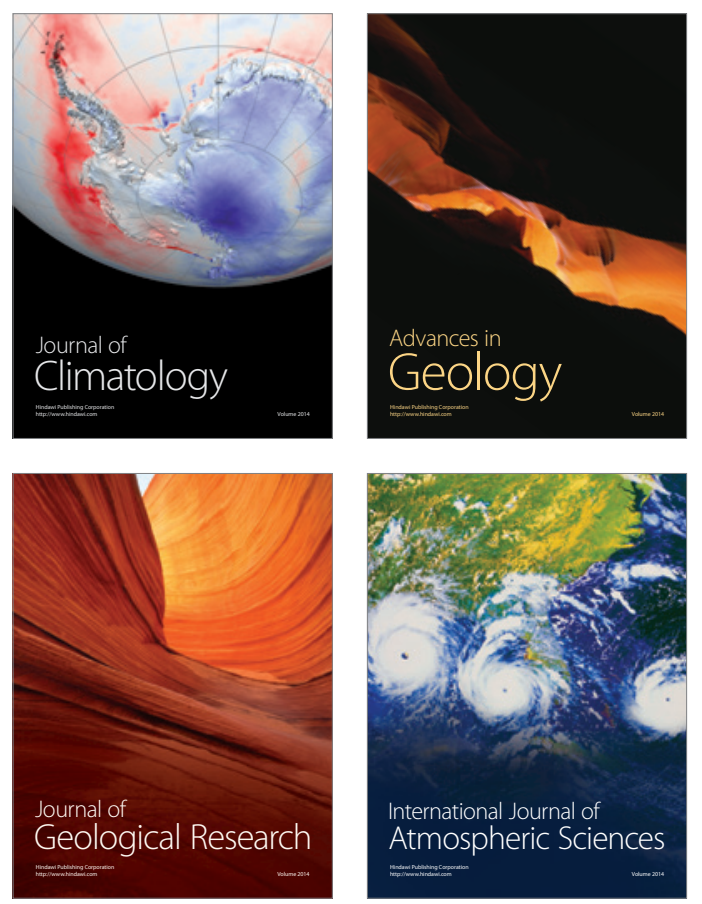

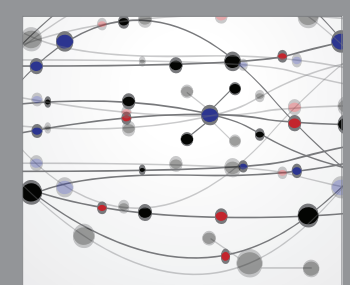

The Scientific

\section{World Journal}
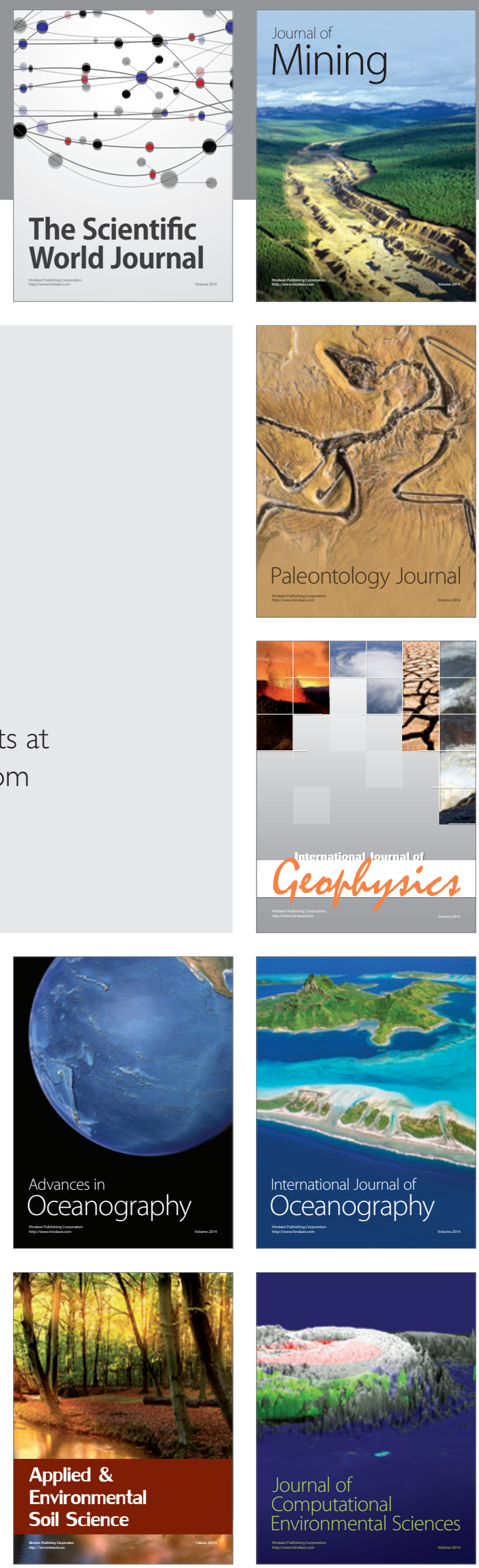